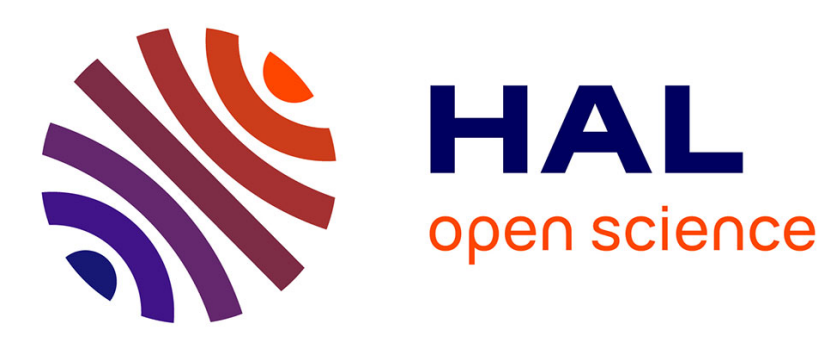

\title{
Analysis of the flicker level generated by the grid-connection of a fleet of electric vehicles
}

Anne Blavette, Roman Le Goff Latimier, H. Ben Ahmed, Bernard Multon

\section{To cite this version:}

Anne Blavette, Roman Le Goff Latimier, H. Ben Ahmed, Bernard Multon. Analysis of the flicker level generated by the grid-connection of a fleet of electric vehicles. IEEE ISGT Europe, 2016, Lubiana, Slovenia. hal-01791763

\section{HAL Id: hal-01791763 \\ https://hal.science/hal-01791763}

Submitted on 14 May 2018

HAL is a multi-disciplinary open access archive for the deposit and dissemination of scientific research documents, whether they are published or not. The documents may come from teaching and research institutions in France or abroad, or from public or private research centers.
L'archive ouverte pluridisciplinaire HAL, est destinée au dépôt et à la diffusion de documents scientifiques de niveau recherche, publiés ou non, émanant des établissements d'enseignement et de recherche français ou étrangers, des laboratoires publics ou privés. 


\title{
Analysis of the flicker level generated by the grid-connection of a fleet of electric vehicles
}

\author{
Anne Blavette, Roman Le Goff Latimier, Hamid Ben Ahmed, Bernard Multon \\ SATIE (CNRS unit 8029), Ecole Normale Supérieure de Rennes, France
}

\begin{abstract}
Optimised strategies regarding the coordinated grid connection of a fleet of electric vehicles often consider the simultaneous connection of a large number of these vehicles. This may induce voltage fluctuations of significant amplitude and provoke objectionable light intensity variations when applied to lighting equipment, which is defined as flicker. Hence, it is important to study under which conditions flicker may arise in order to define optimised grid connection strategies which prevent this phenomenon from occuring. However, although the grid impact of electric vehicle fleets is an active area of research, very few papers have considered the flicker level which the grid connection of electric vehicles may generate. Hence, this paper addresses the flicker level induced by the step-by-step grid connection of a fleet of electric vehicles connected to the distribution network. Flicker level will be studied under different conditions in terms of grid short-circuit level, grid impedance angle and power consumption profiles of the electric vehicle fleet.

Index Terms-Flicker, electric vehicles
\end{abstract}

\section{INTRODUCTION}

$\mathbf{F}$ LICKER is defined as visual discomfort due to the light intensity fluctuations of the lighting equipment undergoing voltage variations caused by loads and power sources having a variable power profile. Hence, grid operators require that its level is maintained below an allowed limit. However, optimised strategies regarding the coordinated grid connection of a fleet of electric vehicules (EVs) often consider the simultaneous connection of a large number of these vehicles, which may lead to flicker. Despite this, the flicker level corresponding to the grid connection of an electric vehicle fleet has been rarely studied in the literature. This is thought to stem from the currently low penetration level of EVs in most countries, as under these conditions, no coordinated strategy is necessary. Hence, the presently small number of existing EVs connects to the grid in a random fashion, thus generating no flicker.

As highlighted in a review paper [1], the issues which are usually addressed in papers dealing with the grid integration of an EV fleet are its impact on: peak demand [2], power losses [3]-[6], voltage deviations [3], [4], [6], loss of life of on-load tap-changing (OLTC) transformers [7], network congestion and in particular thermal loading of the distribution electrical equipment [6], [8], unbalance and harmonic distortion [4]. Only one paper has been found to address flicker [9]. More specifically, this paper details the individual flicker levels emitted by three different EVs having each a different battery management strategy. It showed that the flicker level $P_{s t}$ emitted by a single EV could be significant

978-1-5090-3358-4/16/\$31.00 (C)2016 IEEE (reaching almost 1.2 when the background flicker does not exceed 0.4). However, the flicker level emitted by a fleet of electric vehicles had never been studied, to the best of the authors' knowledge, and is thus addressed in this paper. More precisely, this study focuses exclusively on the flicker generated by the successive grid connections of several groups of EVs. Hence, the contribution in terms of flicker of the battery management strategy is not taken into account here. So, it is assumed that the power consumption of an EV is constant once connected. The flicker level is studied for grids of different strength levels in terms of short-circuit levels and in terms of impedance angles. However, unrealistic cases are excluded from the analysis based on the value of their shortcircuit ratio and on their pre-connection loading ratio.

\section{MODELING}

\section{A. Flicker}

1) Flickermeter design: A flickermeter compliant with IEC standards 61000-4-15 [10] and 61400-21 [11] was used in this study. Its design is described in a previous work [12]. This tool converts a 10-minute long voltage profile into an index called short-term flicker level and referred to as $P_{s t}$.

2) Flicker requirements: Grid operators require that flicker level in their network does not exceed an allowed limit in order to ensure a sufficient level of quality of their power supply. These limits may differ between different grid operators. Hence, a survey on flicker requirements enforced in several countries has been undertaken as part of this study and its results are described later in this section.

It is important to note that two types of flicker limits are found in grid codes and other similar regulations. The first one is the total maximum flicker level at a given node, usually the point of common coupling (PCC). This limit represents the non-linear combination of the individual flicker levels generated by each load or power source. The second one regards the individual flicker emitted by a given grid-connected installation. Grid operators may decide to enforce one or the other type of flicker limit, or both.

As regards electric vehicles, no flicker requirement has been issued yet. This is very likely due to their currently very low level of penetration in most power systems. Hence, in the absence of EV-specific requirements, it was thought reasonable in this paper to consider flicker requirements applied to power sources (such as wind turbines) and loads connected at the distribution level. Table I shows the limits in terms of total flicker level and individual flicker level as enforced by 
TABLE I

SHORT-TERM FLICKER LEVEL LIMITS

\begin{tabular}{|c|c|c|c|}
\hline Title & Region & $\begin{array}{c}\text { Total flicker } \\
\text { level }\end{array}$ & $\begin{array}{c}\text { Individual } \\
\text { flicker level }\end{array}$ \\
\hline Distribution code [13] & Ireland & nonexistent & $\begin{array}{c}0.7^{1} \\
0.35^{2}\end{array}$ \\
\hline Grid code [14] & $\begin{array}{c}\text { Great } \\
\text { Britain }\end{array}$ & 1 & nonexistent \\
\hline $\begin{array}{c}\text { Nordic Grid Code } \\
\text { [15] }\end{array}$ & $\begin{array}{c}\text { Nordel } \\
\text { group }\end{array}$ & 1 & nonexistent \\
\hline TF 3.2.5 [16] & Denmark & 1 & 0.3 \\
\hline Decree 23/04/2008 [17] & France & 1 & $0.35^{3}$ \\
$0.35^{*} 40 / S_{s c}$ \\
$\geq 0.35$
\end{tabular}

${ }^{1}$ Applicable to loads only, ${ }^{2}$ Applicable to wind/wave installations, ${ }^{3}$ For short-circuit levels $S_{s c} \geq 40 \mathrm{MVA},{ }^{4}$ For short-circuit levels $S_{s c}<40 \mathrm{MVA}$ $\left(S_{s c}\right.$ is in MVA)

different grid operators [13]- [17] or as recommended by IEC standard 61000-3-7 [18]. The most stringent limit is enforced in the countries belonging to the Nordel group (i.e. Denmark, Finland, Iceland, Norway and Sweden) and is equal to 0.3. It corresponds to an individual limit. It is interesting to note that this limit is lower than the minimum limit of $P_{s t}=0.35$ which is recommended in IEC standard 61000-3-7. The most permissive limit is equal to 1 and corresponds to a total flicker limit. Hence, if the flicker level is smaller than 0.3, then the EV fleet complies with flicker requirements in any case. If, on the contrary, the flicker level ranges between 0.3 and 1, the EV fleet compliance depends on the regulations of the country in which the EV fleet is used. In addition, besides the flicker limit, the compliance of the EV fleet may depend on the background flicker level due to the other gridconnected installations. In summary, when the flicker level ranges between 0.3 and 1 , complying with flicker requirements is strictly site-dependent. However, if the flicker level exceeds 1 , the EV fleet can be considered as failing definitely to comply with flicker requirements.

\section{B. Grid modeling}

A grid model was developed in DIgSILENT power system simulator PowerFactory [19] and is shown in Fig. 1. The EV fleet is connected to the $20 \mathrm{kV}$ bus which represents the point of common coupling. The impedance between the electric vehicles and the point of common coupling is assumed negligible compared to the other impedances considered here and is thus not modeled. A $20 \mathrm{kV} / 30 \mathrm{kV}$ transformer connects the EV fleet to the rest of the national/regional grid. The transformer rated power is equal to $20 \mathrm{MVA}$ and its impedance is equal to $0.06+j 2.10^{-4}$ pu where $j$ is the imaginary unit. The rest of the national/regional grid is modeled by a $30 \mathrm{kV}$ voltage source in series with an impedance. This grid model is inspired from the electrical network of the Irish Atlantic Marine Energy Test Site (AMETS) [20] which was initially modeled for a previous work [21]. However, its network architecture was deemed representative of the distribution grid in many other countries [22].

The angle $\Psi$ and the magnitude $Z$ of the grid impedance

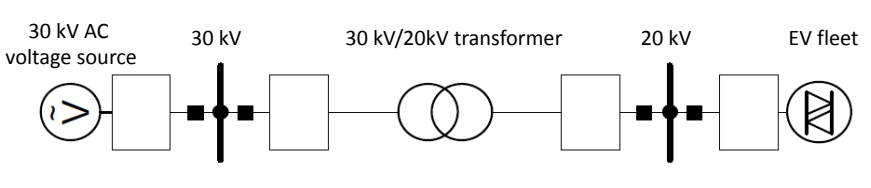

Fig. 1. Grid model developed in PowerFactory

connected to the voltage source define the "strength" of the electric network. The values considered here for these latter two parameters are: $\Psi=\{30 ; 50 ; 70 ; 85\}{ }^{\circ}$, and $Z=\{5 ; 10$; $20 ; 30\} \Omega$ which corresponds to short-circuit levels $S_{s c}=\{30$; $45 ; 90 ; 180\}$ MVA. These short-circuit levels correspond to distribution networks generally defined as weak to mediumstrength grids. No other power sources or loads are connected to the network as this study focuses exclusively on the flicker generated by the grid connection of an EV fleet.

\section{EV fleet modeling}

The EV fleet is composed of $N_{e v}$ vehicles whose individual power consumption will be referred to as $P_{e v}$ in the rest of the paper. Power $P_{e v}$ was selected as equal to $3 \mathrm{~kW}$ which corresponds to the power required for slow charging by an electric vehicle of medium autonomy range [23]-[25]. It is assumed that this vehicle does not consume nor inject reactive power to the grid. No "Vehicule-to-Grid" strategy is considered, hence the electric vehicles are modeled as loads only.

Several options exist for connecting an EV fleet to the grid. One of these options consists in allowing all the electric vehicles to connect to the grid as soon as they arrive at their charging site (typically the owner's home), as it is now the case. However, more coordinated strategies are usually envisaged for optimization purposes, for instance for minimizing power losses, peak demand, etc. [26]. In most of these grid connection strategies, the time at which the EVs connect to the grid is an optimization variable. Also, in most studies, all the vehicles belonging to the fleet, or at least to a fraction of it, are allowed to connect simultaneously. In particular, in largescale EV fleets, it may be expected that several EV groups may connect one after another to prevent any power system stability issues [27]. This approach was retained in this study and the EV fleet is divided into several groups which connect successively one after another with a time delay $\Delta T$, as shown in Fig. 2. A maximum number of up to $10 \mathrm{EV}$ groups was arbitrarily selected for this study. It is important to note that the number of EVs $N_{e v}$ depends only on the grid impedance angle and magnitude, and on the total number of group grid connections $k$ which ranges between 1 and $10(k \in \mathbb{N})$.

The voltage change at the point of common coupling due to the connection of a single group of EVs is modeled by means of a Heavyside step function. In other words, and as mentioned earlier, the power consumed by the EVs is assumed to be constant once charging has started. This may not always be the case in reality as varying the EVs power consumption may be advisable, for instance for reducing peak loads and power 


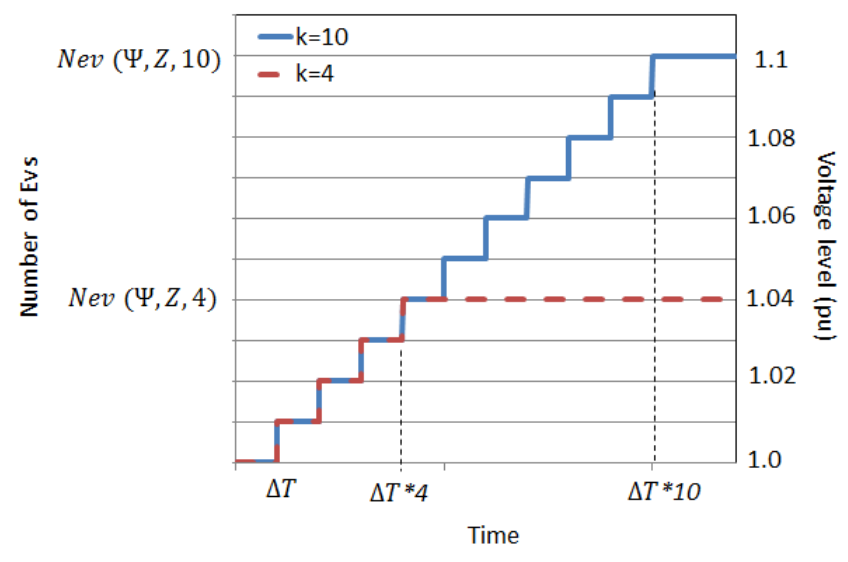

Fig. 2. Number of grid-connected EVs as a function of time for different total numbers of steps $k$

losses. However, as mentioned earlier, this paper focuses on the flicker generated exclusively by the grid connection of an EV fleet, and not by its subsequent switching operation.

The voltage at the PCC is modeled by a series of Heavyside functions, each delayed from the previous one by a time duration $\Delta T$ chosen equal to $30 \mathrm{~s}$ in this study. However, it is important to consider that the time delay $\Delta T$ between the grid connection of different $\mathrm{EV}$ groups may not always be constant, for instance for practical reasons such as the availability of variable renewable resources, latency in the communication infrastructure, etc. In this case, the resulting flicker level should be less than the flicker level corresponding to the minimum time delay and greater than the flicker level corresponding to the maximum time delay. Hence, analysing a voltage profile presenting a constant time delay between each EV group grid connection, as it done in this study, provides a reference for such cases.

The analysis presented in this paper was conducted from the grid operator's perspective, one of whose obligations is to maintain voltage within an allowed range. This allowed range usually represents $\pm 10 \%$ of the nominal voltage as described in a previous work [12]. Each EV group composing the farm is assumed to induce a voltage deviation equal to $0.01 \mathrm{pu}$. Hence, when the fleet is composed of a maximum number of $10 \mathrm{EV}$ groups, the total voltage deviation is equal to $0.1 \mathrm{pu}$, thus remaining in the allowed range considering a pre-connection voltage equal to $1 \mathrm{pu}$. Ten voltage profiles were generated. They have one to ten steps which represents one to ten EV group grid connections. The corresponding total voltage deviations are thus equal to $0.01 \mathrm{pu}$ and to $0.1 \mathrm{pu}$, the latter representing the maximum allowed voltage deviation.

For each of these total voltage deviations, there exist different associated numbers $N_{e v}$ of EVs which correspond to different grid impedance angle and magnitude. Analyzing these numbers, and thus the corresponding rated power levels, allows to exclude some irrelevant cases from the study. In essence, the cases where the EV fleet rated power is sufficiently close to the
TABLE II

FLICKER LEVEL CORRESPONDING TO VOLTAGE PROFILES WITH $k$ STEPS

\begin{tabular}{|c|c|}
\hline Number of steps $k$ & Flicker level $P_{s t}$ \\
\hline 1 & 0.14 \\
2 & 0.22 \\
3 & 0.26 \\
4 & 0.28 \\
5 & 0.30 \\
6 & 0.31 \\
7 & 0.32 \\
8 & 0.33 \\
9 & 0.34 \\
10 & 0.35 \\
\hline
\end{tabular}

short-circuit level must be excluded from the study. Also, cases where it is considered likely that the EV fleet grid connection leads to equipment overloading must be excluded as well. This last study, contrary to the short-circuit ratio analysis, is rarely done in conjunction with flicker studies, not to mention flicker studies applied to electric vehicles.

\section{Methodology}

An iterative approach was used to determine the maximum number of electric vehicles $N_{e v}$ which may compose the fleet for different impedance angles and magnitudes while meeting the grid operator's voltage requirements. This approach consists in performing successive load flows with PowerFactory using the grid model shown in Fig. 1 for several values of the grid impedance angle $\Psi$ and magnitude $Z$, and of the number of steps $k$. For each combination $\{\Psi ; Z ; k\}$, the number $N_{e v}$ of electric vehicles is varied in an iterative fashion until the voltage deviation at the point of common coupling is equal to $0.01 k \mathrm{pu}$. The results will be described by means of two parameters, the short-circuit ratio and the pre-connection loading ratio, which will be explained later in this section. Load flows are solved by means of the Newton-Raphson algorithm. In parallel, the flicker levels corresponding to the voltage profiles composed of successive Heavyside functions, and mentioned earlier in this section, were computed. The results corresponding to this latter analysis are shown in Table II.

Besides flicker, it is also expected that issues such as congestion may arise. Congestion occurs when the power transfer demand from the grid may overload the electrical transmission and distribution equipment. Congestion may also occur when the power transfer demand is close to the maximum power transfer capability of the local network in terms of voltage stability [28]. Congestion can be solved by means of grid reinforcement which is highly likely to solve flicker issues as well. Consequently, flicker may remain an issue only in the cases where the flicker level generated by the EV fleet is not negligible while grid reinforcement is unlikely to be envisaged, i.e. when it is relatively improbable that congestion issues may arise. Hence, flicker and congestion studies were carried out in conjunction in this study. However, congestion studies are usually performed for a specific site and their results cannot be generalized easily. In this context, an analysis was 
performed to estimate approximately the loading conditions prior to the grid connection of the EV fleet. Based on this, it was intended to determine whether the connection of the EV fleet is likely to provoke congestion due to electrical equipment overloading. The method developed to approximate the preconnection loading conditions is described in Section III-A.

In order to exclude other unrealistic cases from the flicker study, an analysis on the ratio of the short-circuit level to the EV fleet power consumption (also called short-circuit ratio) was performed, as described in Section III-B. Cases corresponding to a sufficiently low short-circuit ratio can be considered as unrealistic as grid operators would limit the rated power of the EV fleet in order to prevent power system issues. Alternatively, they could also choose to reinforce the grid. Hence, these cases must be excluded from the flicker study. In this paper, only cases corresponding to an arbitrarilyselected short-circuit ratio greater than two are considered, as it represents the lowest value for which the grid connection of variables power sources and loads seems to be allowed [29], [30]. It is also important to note that, contrary to the approximated pre-connection loading conditions, the shortcircuit level can be estimated based on actual network data provided by grid operators [31], [32].

\section{A. Pre-connection loading ratio}

In this section, congestion issues due to the grid connection of an EV fleet are taken into account. In particular, the loading of the electrical equipment connecting the $\mathrm{EV}$ fleet to the transmission grid is considered. This equipment is modeled implicitily in the grid impedance. It is assumed that loads connected prior to the EV fleet connection draw a current $I$ from the rest of the national/regional network. It is also assumed that the rating of the electrical distribution equipment (lines, transformers) is greater than, or at least equal to, this current $I$. Under these conditions, it is finally assumed that the distribution equipment can accommodate an additional load demand from the EV fleet, provided that it is sufficiently small. In other words, the ratio of the EV fleet power consumption to the pre-connection loading due to the already grid-connected loads must be sufficiently small. This ratio can be expressed as

$$
n=\frac{P_{e v} N_{e v}}{S}
$$

where $N_{e v}$ the maximum number of vehicles for which the fleet complies with voltage requirements. The pre-connection loading $S$ is the apparent power which must be delivered to the already grid-connected loads. Numerical values for this loading are of course site-dependent and may be very variable, but its order of magnitude was approximated in this paper as it will be explained later.

As mentioned earlier, it was assumed that, under normal conditions, lines and transformers are operated at a lower level than their maximum allowed loading. Reasons for this usually include for instance provision for further power transfer (e.g. due to ever-increasing load demand). So, there should usually exist a significant margin between the maximum allowed loading and the pre-connection loading. In other words, it was assumed that a line or a transformer can be safely operated at a loading greater of $x \%$ than its pre-connection loading, without leading to congestion issues. However, in the absence of available numerical data, a value of $20 \%$ was arbitrarily considered for this security margin. Hence, flicker was studied for cases where the pre-connection loading ratio is less than or equal to $20 \%$. The pre-connection loading $S$ was estimated by assuming that

$$
S=\sqrt{3} V I \approx P=\frac{3 R I^{2}}{p_{\text {loss }}}
$$

where $V$ is the voltage, $I$ is the current, $R$ is the real part of the grid impedance $\mathbf{Z}, p_{\text {loss }}$ is the percentage of losses in the transmission and distribution grid and $P$ is the real part of complex power $\mathbf{S}$. In developed countries, the annual average for $p_{\text {loss }}$ is around 6\% [33], [34]. Following this, the pre-connection loading can be calculated as

$$
S=\frac{V^{2} p_{\text {loss }}}{R}
$$

It must be noted that this loading $S$ is assumed to flow through the electrical components (lines, transformers) connecting the EV fleet to the transmission grid. This supposes that the rest of the national/regional grid is composed of electrical components in series connected to an ideal, constant voltage source. Strictly speaking, this is not the case in reality as the grid is meshed, especially at the transmission level while the distribution level is more radially-designed. However, the EV fleet rated power is relatively low compared to the shortcircuit level of a node belonging to the transmission grid, even at the lowest voltage level (from several tens of $\mathrm{kV}$ [22]). Hence, it is sufficient to model the transmission grid as an ideal, constant voltage source. Consequently, considering the rest of the national/regional grid as a radial network is relevant in our case.

Also, it is important to note that the approach described in this section implies that the EV fleet is powered from the rest of the national/regional grid only. This is valid with respect to the conditions considered in this study in which no other power sources are present. However, this constitutes a worstcase scenario with respect to the loading of the distribution electrical equipment connecting the fleet to the transmission grid. This loading could indeed be dramatically reduced if local power sources (e.g. wind farms) were connected to the same distribution grid than the EV fleet. Consequently, under these conditions, grid reinforcement could be delayed or could even become unnecessary. Hence, as this may also allow larger-scale EV fleets to connect to the grid, flicker level could reach higher levels. However, it is important to note that this configuration could lead to other issues, in particular regarding voltage, due to the power flow becoming bi-directional. 
TABLE III

SHORT-CIRCUIT RATIO $r=S_{s c} /\left(P_{e v} N_{e v}\right)$ AVERAGED OVER THE FOUR SHORT-CIRCUIT LEVELS $S_{s c}=\{30 ; 45 ; 90 ; 180\}$ MVA

\begin{tabular}{|c|c|c|c|c|c|}
\cline { 3 - 6 } \multicolumn{2}{c}{} & \multicolumn{5}{c|}{ Impedance angle $\Psi\left(^{\circ}\right)$} \\
\cline { 3 - 6 } \multicolumn{2}{c}{} & \multicolumn{5}{c|}{30} & 50 & 70 & 85 \\
\hline $\begin{array}{c}\text { Number of } \\
\text { steps } k\end{array}$ & Flicker level Pst & \multicolumn{4}{c|}{} \\
\hline 1 & 0.14 & 89 & 66 & 37 & 15 \\
\hline 2 & 0.22 & 45 & 34 & 19 & 9 \\
\hline 3 & 0.26 & 30 & 23 & 14 & 7 \\
\hline 4 & 0.28 & 23 & 18 & 11 & 6 \\
\hline 5 & 0.30 & 19 & 14 & 9 & 5 \\
\hline 6 & 0.31 & 16 & 12 & 8 & 5 \\
\hline 7 & 0.32 & 14 & 11 & 7 & 4 \\
\hline 8 & 0.33 & 12 & 10 & 6 & 4 \\
\hline 9 & 0.34 & 11 & 9 & 6 & 4 \\
\hline 10 & 0.35 & 10 & 8 & 5 & 4 \\
\hline
\end{tabular}

\section{B. Short-circuit ratio}

The short-circuit ratio $r$ is calculated such as

$$
r=\frac{S_{s c}}{P_{e v} N_{e v}}
$$

Should the short-circuit ratio $r$ be too low, it would be mean that, in order to reach a given flicker level $P_{s t}$, the EV fleet power consumption should be relatively close to the shortcircuit level $S_{s c}$, which is unrealistic. Hence, irrelevant cases where the short-circuit ratio is less than or equal to two, as mentioned earlier, are excluded from the flicker analysis.

\section{RESULTS}

\section{A. Short-circuit ratio}

This section presents the results of the short-circuit ratio analysis. As expected, the values of the short-circuit ratio were similar for the different short-circuit levels $S_{s c}=\{30 ; 45$; 90; 180 MVA. This stems from the proportional relationship which exists between the number $N_{e v}$ of electric vehicles and the flicker level $P_{s t}$ whereas the latter is inversely proportional to the short-circuit level $S_{s c}$, as already described in IEC standard 61400-21. Hence, only the short-circuit ratios averaged over the four short-circuit levels considered in this study are presented in Fig. III. As expected, the short-circuit ratio decreases as a function of the impedance angle. It appears also that, although the short-circuit ratio may be quite low, it is never less than four, whereas the minimum threshold considered here for excluding cases is equal to two, as mentioned earlier. Hence, on this basis, all the cases should be considered. However, in some cases, flicker can reach significant levels with respect to the allowed limits: flicker can thus be considered as representing a potential issue.

The values of the short-circuit ratios corresponding to the most stringent limit, i.e. $P_{s t, \max }=0.3$, are highlighted with a red border in Fig. III. These cells show the minimum shortcircuit ratios for which the flicker level generated by the connection of an EV fleet is less than any existing allowed limit.
Below these minimum short-circuit ratios, national/regional grid code requirements and/or the pre-connection flicker level have to be taken into account to determine whether the EV fleet is compliant with flicker requirements.

\section{B. Pre-connection loading ratio}

The results regarding the pre-connection loading ratio are shown in Fig. IV. It is important to mention that the definition of the pre-connection loading ratio is based on the assumption that the loading $S$ is almost equal to the EV fleet rated power (i.e. $S \approx P_{e v} N_{e v}$ ). This assumption may no longer be valid for grids having a sufficiently high impedance angle as the reactive power flowing through the grid impedance is no longer negligible. Hence, in this case, the pre-connection loading ratio should be greater than under the initial assumption considered here. In Fig. IV, the grey-colored cells correspond to the cases for which the pre-connection loading ratio exceeds $20 \%$ and which are thus considered as irrelevant as mentioned in Section III-A. Under these conditions, it appears that only a limited number of cases can be considered for the flicker study. In particular, it can be observed in Fig. IV that the maximum flicker level which the EV fleet grid connection may be expected to generate ranges between 0.1 and 0.2 . This is less than the allowed flicker limits, regardless of whether total or individual flicker limits are considered. Hence, when the pre-connection loading ratio is taken into account, it can be concluded that flicker generated by the grid connection of an EV fleet may not represent an issue as grid reinforcement would occur before flicker becomes significant.

\section{CONCLUSIONS}

This paper focused on the conditions under which flicker may arise due to the grid connection of a fleet of electric vehicles to the distribution network. In particular, this study has focused on the contribution in terms of flicker of the step-by-step grid connection of an EV fleet. In order to exclude irrelevant cases from the study, two parameters were considered: the pre-connection loading ratio and the shortcircuit ratio. More specifically, it was shown that considering the pre-connection loading ratio in flicker studies is extremely relevant. In addition, it was discussed that powering the EV fleet from local sources connected to the same distribution grid may considerably reduce or even suppress congestion issues by decreasing the loading of the electrical components connecting the fleet to the transmission grid. Hence, larger-scale EV fleets could be allowed to connect to the grid and higher flicker levels might be observed under these conditions.

\section{ACKNOWLEDGMENT}

The work of Anne Blavette has been carried out in the frame of the "SmartWave" project funded by a FP7 Marie Curie Intra-European Fellowship (IEF).

\section{REFERENCES}

[1] R. C. Green, L. Wang, and M. Alam. The impact of plug-in hybrid electric vehicles on distribution networks: A review and outlook. Renewable and Sustainable Energy Reviews, vol. 15(1), pp.544-553, 2011. 
TABLE IV

Pre-connection loading Ratio $\left(P_{e v} N_{e v} / S\right)$ in $\%$

\begin{tabular}{|c|c|c|c|c|c|c|c|c|c|c|c|c|c|c|c|c|c|}
\hline & \multirow{2}{*}{$\begin{array}{c}\text { Impedance angle }\left(^{\circ}\right) \\
\text { Short-circuit level } \\
\text { (MVA) }\end{array}$} & \multicolumn{4}{|c|}{30} & \multicolumn{4}{|c|}{50} & \multicolumn{4}{|c|}{70} & \multicolumn{4}{|c|}{85} \\
\hline & & 30 & 45 & 90 & 180 & 30 & 45 & 90 & 180 & 30 & 45 & 90 & 180 & 30 & 45 & 90 & 180 \\
\hline $\begin{array}{l}\text { Number of } \\
\text { steps } k\end{array}$ & Flicker level Pst & & & & & & & & & & & & & & & & \\
\hline 1 & 0.14 & 16 & 16 & 16 & 17 & 16 & 16 & 16 & 16 & 15 & 15 & 15 & 15 & 11 & 11 & 10 & 9 \\
\hline 2 & 0.23 & 32 & 32 & 32 & 32 & 32 & 32 & 32 & 31 & 30 & 30 & 29 & 28 & 17 & 17 & 16 & 14 \\
\hline 3 & 0.27 & 48 & 48 & 48 & 48 & 47 & 46 & 46 & 46 & 43 & 43 & 42 & 39 & 23 & 24 & 21 & 18 \\
\hline 4 & 0.30 & 64 & 64 & 63 & 63 & 62 & 62 & 61 & 59 & 55 & 55 & 53 & 49 & 27 & 27 & 24 & 21 \\
\hline 5 & 0.32 & 78 & 78 & 77 & 77 & 76 & 76 & 75 & 72 & 67 & 66 & 63 & 59 & 31 & 30 & 28 & 23 \\
\hline 6 & 0.33 & 92 & 92 & 91 & 90 & 89 & 89 & 87 & 84 & 77 & 76 & 72 & 67 & 34 & 33 & 30 & 26 \\
\hline 7 & 0.35 & 107 & 106 & 106 & 103 & 103 & 102 & 100 & 96 & 86 & 86 & 82 & 74 & 37 & 36 & 33 & 28 \\
\hline 8 & 0.36 & 120 & 120 & 119 & 115 & 115 & 114 & 112 & 107 & 95 & 94 & 89 & 81 & 40 & 39 & 35 & 30 \\
\hline 9 & 0.38 & 134 & 133 & 132 & 129 & 127 & 126 & 123 & 118 & 104 & 102 & \begin{tabular}{|l|}
97 \\
\end{tabular} & 88 & 42 & 41 & 37 & 31 \\
\hline 10 & 0.39 & 147 & 146 & 144 & 141 & 138 & 137 & 134 & 128 & 112 & 109 & \begin{tabular}{|l|l|}
104 \\
\end{tabular} & 94 & 44 & 43 & \begin{tabular}{|l|}
39 \\
\end{tabular} & 33 \\
\hline
\end{tabular}

[2] K. Qian, C. Zhou, M. Allan, and Y. Yuan. Modeling of load demand due to EV battery charging in distribution systems. IEEE Transactions on Power Systems, vol. 26(2), pp.802-810, May 2011.

[3] K. Clement-Nyns, E. Haesen, and J. Driesen. The impact of charging plug-in hybrid electric vehicles on a residential distribution grid. IEEE Transactions on Power Systems, vol. 25(1), pp.371-380, Feb 2010.

[4] P. Moses, S. Deilami, A. Masoum, and M. Masoum. Power quality of smart grids with plug-in electric vehicles considering battery charging profile. In 2010 IEEE PES Innovative Smart Grid Technologies Conference Europe, pp.1-7.

[5] L. Pieltain Fernandez, T. Gomez San Roman, R. Cossent, C. Mateo Domingo, and P. Frias. Assessment of the impact of plug-in electric vehicles on distribution networks. IEEE Transactions on Power Systems, vol. 26(1), pp.206-213, Feb 2011.

[6] J. A. P. Lopes, F. J. Soares, P. M. R. Almeida, P. C. Baptista, C. M. Silva, and T. L. Farias. Quantification of technical impacts and environmental benefits of electric vehicles integration on electricity grids. In 2009 $8^{\text {th }}$ Int. Symp. on Advanced Electromechanical Motion Systems Electric Drives Joint Symposium, pp. 1-6, July 2009.

[7] Jun Yang, Lifu He, and Siyao Fu. An improved PSO-based charging strategy of electric vehicles in electrical distribution grid. Applied Energy, vol. 128, pp.82-92, 2014.

[8] J. A. P. Lopes, F. J. Soares, and P. M. R. Almeida. Integration of electric vehicles in the electric power system. Proceedings of the IEEE, vol. 99(1), pp.168-183, Jan 2011.

[9] H. Seljeseth, H. Taxt, and T. Solvang. Measurements of network impact from electric vehicles during slow and fast charging. In $201322^{\text {nd }}$ Int. Conf. and Exhibition on Electricity Distribution (CIRED), pp. 1-4.

[10] Electromagnetic compatibility (EMC) - Part 4-15: Testing and measurement techniques - Flickermeter - Functional and design specifications, IEC standard 61000-4-15, 2010.

[11] Wind turbines - Part 21: Measurement and assessment of power quality characteristics of grid connected wind turbines, IEC standard 61400-21, 2008.

[12] A. Blavette, D. L. O'Sullivan, R. Alcorn, T. W. Lewis, and M. G. Egan. Impact of a medium-size wave farm on grids of different strength levels. IEEE Transactions on Power Systems, vol. 29(2), pp.917-923, March 2014.

[13] "Distribution Code", ESB, 2015.

[14] "The Grid Code", National Grid, issue 5, revision 15, 2016.

[15] "Nordic Grid Code - Nordic collection of rules", Nordel group, 2007.

[16] Regulation TF 3.2.5, Energinet, 2004.

[17] "Arrêté du 23 avril 2008 relatif aux prescriptions techniques de conception et de fonctionnement pour le raccordement à un réseau public de distribution d'électricité en basse tension ou en moyenne tension d'une installation de production d'énergie électrique", French decree, 2008.

[18] "Electromagnetic compatibility (EMC) - Part 3-7: Limits - Assessment of emission limits for the connection of fluctuating installations to MV, HV and EHV power systems", IEC standard 61000-3-7, 2008.

[19] DIgSILENT website, http://www.digsilent.de/index.php/ fr-products-powerfactory.html, accessed $22^{\text {nd }}$ Feb. 2016.

[20] http://www.seai.ie/Renewables/Ocean-Energy/. accessed $29^{\text {th }}$ March 2016.

[21] A. Blavette, D. L. O'Sullivan, M. G. Egan, and T. Lewis. Grid impact assessment of a medium size wave farm connected to different test sites. In $20124^{\text {th }}$ Int. Conf. on Ocean Energy

[22] "Power distribution in Europe - Facts \& figures", Union of the Electricity Industry EURELECTRIC, 2013.

[23] Nissan Leaf commercial advertisment, http://www.nissan.co. $\mathrm{uk} / \mathrm{GB} / \mathrm{en} / \mathrm{vehicle} /$ electric-vehicles/leaf/charging-and-battery/ charging-nissan-leaf-and-battery.html, accessed $19^{\text {th }}$ Feb. 2016.

[24] Kia Soul EV website, http://mobilityhouse.com/en/portfolio/ kia-soul-ev/, accessed $19^{\text {th }}$ Feb. 2016.

[25] Audi 3 e-tron commercial leaflet, http://www.audi.fr/dam/nemo/ fr/Gamme/A3/A3-Sportback-e-tron/Leaflet\%20client_Audi_A3_ Sportback\%20e-tron_services\%20VF\%20cliquable.pdf, accessed $19^{\text {th }}$ Feb. 2016

[26] R. Le Goff Latimier, T. Kovaltchouk, H. Ben Ahmed, and B. Multon. Preliminary sizing of a collaborative system: Photovoltaic power plant and electric vehicle fleet. In $20149^{\text {th }}$ Int. Conf. on Ecological Vehicles and Renewable Energies (EVER).

[27] P. Mitra and G. K. Venayagamoorthy. Wide area control for improving stability of a power system with plug-in electric vehicles. IET Generation, Transmission Distribution, vol. 4(10) pp.1151-1163, Oct. 2010.

[28] P. Kundur. Power System Stability And Control. EPRI power system engineering series. McGraw-Hill Education (India) Pvt Limited, 1994.

[29] J. O. Tande, G. Di Marzio, and K. Uhlen, "Power system requirements for wind power plants.", SINTEF, 2007.

[30] D. Woodford. Power electronics for wind energy applications. Seminar of the IEEE South Alberta section, PES/IAS Calgary chapter, 2012.

[31] “Transmission Forecast Statement 2010-2016”, EirGrid.

[32] "Electricity Ten Year Statement", National Grid, 2015.

[33] "Electric power transmission and distribution losses (\% of output) in the European Union and Japan, 2006-2012", World Bank. http://data.worldbank.org/indicator/EG.ELC.LOSS.ZS/countries/ 1W-EU-XU-JP?display=map, accessed $23^{\text {rd }}$ Feb 2016.

[34] FAQ: "How much electricity is lost in transmission and distribution in the United States?", U.S. Energy Information Adminstration. http: $/ /$ www.eia.gov/tools/faqs/faq.cfm?id=105\&t=3, accessed $23^{\text {rd }}$ Feb 2016 . 